\title{
PRODUCTION AND ECONOMIC COMPLEX AS AN ORGANIZATIONAL AND LEGAL (CORPORATE) MODEL OF ASSOCIATION AND PROSPECTS FOR ITS DEVELOPMENT IN RUSSIA
}

\author{
Tatiana K. Krasilnikova \\ Volzhsky Branch of Volgograd State University, Volzhsky, Russian Federation
}

Introduction: the paper is a comprehensive study of the legal problems of creation and operation of industrial and economic complexes. It notes the need to take into account the experience of functioning such associations of economic entities to ensure the social orientation of corporate associations. The purpose of the work is to determine the legal nature of a production and economic complex, a kind of which is the financial and industrial group in modern conditions and to identify the features of its legal capacity in the context of the civil law theory and practice. To achieve the goal, such methods of scientific knowledge as the historical and legal, comparative and formal legal ones were used. Results: the stages of formation and development of production and economic complexes in Russia are considered, their corporate structure is defined, and their features which are general and distinguished from modern types of business associations are revealed. The paper reveals the economic and legal nature of such complexes, their role in the process of cooperation of the national economy. Conclusions: modern corporate enterprises are a kind of production and economic complexes.

Key words: corporation, production and economic complex, production association, industrial association, financial and industrial group, holding, legal entity.

Citation. Krasilnikova T.K. Production and Economic Complex as an Organizational and Legal (Corporate) Model of Association and Prospects for Its Development in Russia. Legal Concept, 2019, vol. 18, no. 4, pp. 105-110. (in Russian). DOI: https://doi.org/10.15688/lc.jvolsu.2019.4.14

\section{ПРОИЗВОДСТВЕННО-ХОЗЯЙСТВЕННЫЙ КОМПЛЕКС КАК ОРГАНИЗАЦИОННО-ПРАВОВАЯ (КОРПОРАТИВНАЯ) МОДЕЛЬ ОБЪЕДИНЕНИЯ И ПЕРСПЕКТИВЫ ЕГО РАЗВИТИЯ В РОССИИ}

\section{Татьяна Константиновна Красильникова}

Волжский филиал Волгоградского государственного университета, г. Волжский, Российская Федерация ности производственно-хозяйственных комплексов. В ней отмечается необходимость учитывать опыт функционирования такого рода объединений хозяйствующих субъектов для обеспечения социальной направлен$\dot{\varepsilon}$ ности деятельности корпоративных объединений. Целью работы является определение юридической природы производственно-хозяйственного комплекса, разновидностью которого в современных условиях выступает финансово-промышленная группа; выявление особенностей его правоспособности с позиции цивилистической теории и практики. Для достижения цели использовались такие методы научного познания, как историко-правовой, сравнительный и формально-юридический. Результаты: рассмотрены этапы становления и развития производственно-хозяйственных комплексов в России, определена их корпоративная структура, выявлены общие и отличительные их признаки с современными видами предпринимательских объеди(2) нений. В статье раскрывается экономическая и правовая природа такого рода комплексов, их роль в процессе
}

Введение: данная статья является комплексным исследованием правовых проблем создания и деятель- 
кооперирования народного хозяйства. Выводы: современные корпоративные объединения - это разновидности производственно-хозяйственных комплексов.

Ключевые слова: корпорация, производственно-хозяйственный комплекс, производственное объединение, промышленное объединение, финансово-промышленная группа, холдинг, юридическое лицо.

Цитирование. Красильникова Т. К. Производственно-хозяйственный комплекс как организационноправовая (корпоративная) модель объединения и перспективы его развития в России // Legal Concept = Правовая парадигма. - 2019. - Т. 18, № 4. - C. 105-110. - DOI: https://doi.org/10.15688/lc.jvolsu.2019.4.14

\section{Введение}

При решении любых новых задач общество в той или иной степени пользуется уже имеющимся инструментарием - теми организационно-правовыми формами и средствами, тем организационно-правовым механизмом, которые выработались в предшествующий период.

Начиная с первой половины 1990-х гг. в России стали возникать на легальной основе финансово-промышленные группы. Они появились не на пустом месте, их прообразами являлись различного рода предпринимательские союзы XIX-XX вв., а также производственные комплексы советского периода.

\section{Модели производственно-хозяйственных комплексов в России}

Обратимся к истории появления производственно-хозяйственных комплексов в России, включая период ведения планового хозяйства в СССР [2, с. 53].

Среди отечественных ученых одним из первых, кто раскрыл необходимость объединения корпораций в предпринимательские союзы, такие как синдикаты и тресты, был профессор права А.И. Каминка [1, с. 441-442]. Вслед за ним правовую природу таких союзов сумел показать известный цивилист XIX в. профессор Г.Ф. Шершеневич [10].

Если сравнить предпринимательские союзы, в качестве которых в России в XIX начале XX столетия выступали синдикаты и тресты, с производственно-хозяйственными комплексами, в число которых в современных условиях входят финансово-промышленные группы, то можно отметить определенного рода сходство между этими видами объединений. Так, можно обнаружить общие черты в образовании синдиката и финансо- во-промышленной группы, которые создаются на основе договора. Их участники сохраняют статус самостоятельных юридических лиц, и, кроме того, имеет место особый правовой механизм их взаимодействия с ведущей компанией.

Необходимо обратить внимание на то, что в 1970-е гг. в советской экономике активно шел процесс объединения хозяйствующих субъектов как по территориальному, так и по отраслевому принципу, что, в свою очередь, привело к появлению отраслевых и межотраслевых комплексов.

Применение понятия «комплекс» для обозначения самых различных типов объединений (производственное объединение, комбинат) получило широкое распространение в научной литературе. Причем в экономической литературе трактовка комплексов отличается большей широтой. Ученые-экономисты связывали понятие «комплекс» с системой разнообразных связей между производственными звеньями. Группа предприятий, действующих в пределах определенной территории и обладающих отраслевой, территориальной и функциональной упорядоченностью, характеризовались в советской экономической литературе как «системно организованные образования» $[8$, с. 6,47$]$. Так, крупное перерабатывающее предприятие и хозяйства сырьевой зоны, связанные отношениями по договорам, определялись в трудах ученых-экономистов как разновидность промышленных комплексов, хотя рамками единой организационной формы они не были связаны. Фактор организационного оформления, следовательно, не являлся для экономической науки решающим при отнесении совокупности предприятий к промышленным комплексам. Для этого достаточно было их функционально-технологической целостности, хотя бы и не получившей организационного оформления. 
Понятие «комплекс» широко использовалось в ряде нормативных актов 70-80 гг. $\mathrm{XX}$ столетия, среди которых «Общее положение о всесоюзном и республиканском промышленных объединениях», «Положение о производственном объединении (комбинате)», «Положение о научно-производственном объединении», «Общее положение о всесоюзном и республиканском объединениях в сельском хозяйстве» [7]. В данных актах соответствующие формирования характеризовались как единые производственно-хозяйственные комплексы. Данное понятие употреблялось как родовое и под ним понимались производственные объединения с обособленным в гражданском обороте имуществом.

Производственные объединения выступали производственно-хозяйственными комплексами, которые состояли из предприятий, научно-исследовательских, конструкторских и других организаций, осуществлявших соответствующую часть производственно-хозяйственной деятельности объединения и которые были наделены в этих целях оперативно-хозяйственной самостоятельностью. Вместе с тем законодательство СССР допускало подчинение в исключительных случаях самостоятельных предприятий и организаций производственным объединениям [6, с. 38].

В зависимости от уровня формирования принадлежности его к основному либо среднему звену (на уровне союзной республики) в системе управления - вопрос об обособлении имущества и субъекте участия в хозяйственной деятельности решался двояко: в случае основного звена - за объединением как юридическим лицом закреплялось имущество; если же речь шла о среднем звене, то имущество было закреплено за предприятиями и организациями, которые входили в его состав, а также основные и оборотные средства, фонды и другое имущество, которое было закреплено за органом управления объединением; в этом случае орган управления выступал юридическим лицом.

Таким образом, правовое понимание комплексов, в отличие от понимания их учеными-экономистами, означало обязательное наличие выраженной организационной формы, организационного единства.
Термин «комплекс», со слов известного советского и российского ученого-правоведа профессора М.И. Козыря, «мог использоваться для характеристики процессов кооперирования независимо от их организационно-правовых форм, но не отождествляться с ними» [4, c. 71]. Экономический подход позволял характеризовать локальные, региональные и народно-хозяйственный комплексы как явления одного и того же порядка, но с различным масштабом деятельности.

Такого рода комплексы образовывались в форме производственных [7, 1974, № 8, ст. 39] и научно-производственных объединений [7, 1976, № 2, ст. 13], всесоюзных и республиканских промышленных объединений [7, 1973, № 7, ст. 32], которые были во многом сходны с ранее действующими трестами и синдикатами, а также с современными корпоративными объединениями.

Комплексы состояли из ряда предприятий различных отраслей материального производства (производственный комплекс - производственное объединение) или отраслей промышленности (промышленный комплекспромышленное объединение). И производственные и промышленные комплексы классифицировались по следующим основаниям: 1) по территориальному признаку; 2) основной специализации; 3) структуре и уровню развития комплексов.

В государственных планах экономического и социального развития СССР предусматривались разделы «Агропромышленный комплекс СССР», «Военно-промышленный комплекс», «Научно-производственный комплекс». Контрольные цифры по показателям их развития разрабатывались Госпланом СССР и доводились до Советов министров союзных республик с разбивкой по отраслям (по предприятиям и организациям республиканского подчинения).

Указанные меры свидетельствовали о консолидации отраслей в рамках определенного комплекса, основу которого составляло подчинение производственной деятельности и использование материально-технических ресурсов в отраслях соответствующего комплекса задачам планируемого получения конечной продукции. При этом такая консолидация не сопровождалась соответствующим обо- 
соблением имущества данного комплекса в хозяйственном обороте. Фонды на материально-технические ресурсы выделялись предприятиям и организациям отраслей, входящих в состав комплекса, через правительственные органы СССР и республик.

Термин «комплекс», используемый в нормативных актах советского периода, не имел однозначного толкования и отражал несколько понятий. Его применение к таким явлениям народного хозяйства, как экономика страны в целом (ст. 16 Конституции СССР), агропромышленный или иной народно-хозяйственный комплекс, отражал преимущественно экономический, а не правовой подход. Их образование шло главным образом по отраслевому пути - вокруг крупного перерабатывающего предприятия группировались хозяйства, специализировавшиеся на производстве определенного вида продукции. Развитие интеграции по отраслевому направлению приняло форму различного рода объединений.

Производственное объединение необходимо было отличать от промышленного объединения прежде всего тем, что оно являлось единым субъектом права и в его составе производственные единицы имели статус филиалов. В то же время в состав промышленного объединения входили юридически самостоятельные предприятия. Необходимость в них была оправдана в тех отраслях, где невозможно было объединение различных видов производств в комбинаты.

По поводу правосубъектности производственного объединения как комплекса в юридической науке советского периода определились три точки зрения: согласно первой точке зрения, правами юридического лица наделялся орган управления объединением, само же объединение рассматривалось как объект управления со стороны вышестоящего органа и как субъект права связанных с этим правовых отношений [4]; в соответствии со вторым подходом субъектом права выступал сам комплекс в целом, его орган управления лишь представлял интересы [5, с. 38-39]; сторонники же третьей точки зрения утверждали, что в качестве субъекта права выступало головное предприятие (компания), в то время как сам ком- плекс правосубъектностью не обладал [3, c. 63]. В последнем случае отражалась сущность советской модели системы хозяйствования, основу которой составляла государственная форма собственности, господствовавшая в СССР.

Закрепление имущества за комплексом, во главе которого стояло то или иное ведомство, осуществлялось путем выделения материальных и финансовых ресурсов всему комплексу. Если признать комплекс в целом субъектом имущественного обособления, то его объектом должно было быть признано не все имущество (так как у каждого из предприятий, входящих в состав комплекса, имелось свое имущество), а лишь то, которое было закреплено именно за системой.

В соответствии с советским законодательством свойства субъекта прав и обязанностей признавались за органами управления хозяйственного комплекса, а не за комплексом в целом, тем самым его правосубъектность являлась лишь юридической фикцией. Все это было не принципиально, так как правосубъектность не сводилась к закреплению статуса юридического лица в силу того, что субъектами правовых отношений могли быть и те организации, которые не являлись юридическими лицами.

По существу объединение и подчиненные ему самостоятельные предприятия составляли единый производственно-хозяйственный комплекс, отношения внутри которого не подверглись тщательной правовой регламентации. Так, общее Положение о Всесоюзном республиканском промышленном объединении на взаимоотношения предприятий и производственных объединений не распространялось. Законодательство же о производственных объединениях эти отношения почти не регламентировало, исходя, видимо, из того, что подчинение предприятий производственным объединениям носило исключительный характер. Восполняя пробелы в правовом регулировании, объединения в ряде случаев регламентировали деятельность и ответственность подчиненных им предприятий. Однако такую практику нельзя было признать правомерной с точки зрения действующего тогда законодательства; кроме того, она приводила к различному регулированию сходных отношений. 
Также неоправданно было отнесение к исключительной компетенции объединений права устанавливать порядок разрешения внутрихозяйственных споров. Вопрос о порядке разрешения разногласий, возникающих между предприятиями и объединениями, оставался открытым. Как известно, советское правительство относило разрешение хозяйственных споров между организациями, подчиненными одному вышестоящему органу, к компетенции последнего. Следовательно, предприятия были лишены возможности обратиться в ведомственный арбитраж в случае спора между ними и объединением. Нередко объединение, будучи участником спора, само решало конфликт, что было неправильно.

Несмотря на имеющиеся недостатки, практика деятельности объединений подтвердила в основном жизненность и эффективность данной формы регулирования отношений внутри комплекса.

Модель создания финансово-промышленных групп путем объединения совокупности юридических лиц свидетельствует о возможном использовании так называемого холдингового варианта при формировании подобных комплексов. В качестве примера признания холдинговых компаний можно привести нормативные акты, на основе которых осуществлялось реформирование сферы оборонного производства. В соответствии с Указом Президента РФ от 23 октября 2000 г. № 1768 «О мерах по обеспечению концентрации и рационализации оборонного производства в Российской Федерации» [9] и Постановлением Правительства РФ от 11 октября 2001 г. № 713 «О федеральной целевой программе "Реформирование и развитие оборонно-промышленного комплекса"》 в сфере оборонного производства стали активно создаваться холдинговые компании, включающие в свой состав предприятия оборонно-промышленного комплекса.

\section{Вывод}

При выборе организационно-правовой формы создаваемого корпоративного объединения очень важно наряду с социально-экономическими факторами учитывать уже имеющийся опыт функционирования производствен- но-хозяйственного комплекса, который заложил традиции регулирования создания и деятельности крупных объединений коммерческих корпораций.

\section{Заключение}

С юридической точки зрения производственно-хозяйственный комплекс - это не исторический архаизм, о котором не стоит говорить в современных условиях. Вся совокупность организационных форм и правовых средств различных форм хозяйственных объединений составляет организационно-правовой механизм производственно-хозяйственной интеграции. Для характеристики всякого производственного объединения может быть использовано понятие «производственно-хозяйственный комплекс» как наиболее общее и охватывающее различные хозяйственные образования. В современных условиях, с включением финансовых структур в производственный процесс, речь может идти и о «производственно-финансовом комплексе».

\section{СПИСОК ЛИТЕРАТУРЫ}

1. Каминка, А. И. Очерки торгового права / А. И. Каминка. - М., 2002. -545 с.

2. Красильникова, Т. К. Административная регламентация организации и деятельности корпораций и применение мер уголовных репрессий в СССР в 20-е годы XX века / Т. К. Красильникова // Вестник Волгоградского государственного университета. Серия 5, Юриспруденция. - 2012. - № 1 (16). - С. 53-56.

3. Лаптев, В. В. Правовая организация хозяйственных систем / В. В. Лаптев. - М., 1978. - 168 с.

4. Правовое положение аграрно-промышленных предприятий и объединений / под ред. М. И. Козыря, В. Н. Яковлева, В. А. Кикотя. - Кишинев, 1974. - $172 \mathrm{c}$.

5. Разуваев, В. Н. Содержание и границы гражданской правосубъектности / В. Н. Разуваев. - М., 1986. $-301 \mathrm{c.}$

6. Рутман, Т. М. Правосубъектность государственного промышленного объединения / Т. М. Ругман // Известия вузов. Правоведение. - 1974. - № 6. C. 38-44.

7. Собрание постановлений Правительства СССР - СП СССР. - 1973. - № 7. - Ст. 32 ; 1974. № 8 . - Ст. 38,$39 ; 1975$. - № 21. - Ст. 45; 1976. - № 2 . Ст. $13 ; 1979$. - № 3. - Ст. $15 ; 1980$. - № 15. - Ст. 98. 
8. Территориальная структура производственных комплексов / под общ. ред. М. М. Паламарчука. - Киев, 1981. -236 с.

9. Указ Президента РФ от 23 октября 2000 г. № 1768 «О мерах по обеспечению концентрации и рационализации оборонного производства в Российской Федерации» // Собрание законодательства Российской Федерации. - 2000. - № 44. Ст. 4349.

10. Шершеневич, Г. Ф. Курс торгового права. В 4 т. Т. 1 / Г. Ф. Шершеневич. - 4-е изд. - СПб., 1908. $-491 \mathrm{c}$.

\section{REFERENCES}

1. Kaminka A.I. Ocherki torgovogo prava [Essays on Commercial Law]. Moscow, 2002. 545 p.

2. Krasilnikova T.K. Administrativnaya reglamentatsiya organizatsii i deyatelnosti korporatsiy i primenenie mer ugolovnykh repressiy v SSSR $v 20$-e gody XX veka [Administrative Regulation of an Organization and Corporation Activities and Penal Sanctions of Criminal Persecutions in the USSR in the 20s of the XXth Century]. Vestnik Volgogradskogo gosudarstvennogo universiteta. Seriya 5. Yurisprudentsiya, 2012, no. 1 (16), pp. 53-56.

3. Laptev V.V. Pravovaya organizatsiya hozyaystvennykh sistem [Legal Organization of Business Systems]. Moscow, 1978. 168 p.

4. Kozyr M.I., Yakovlev V.N., Kikotya V.A., eds. Pravovoe polozhenie agrarno-promyshlennykh predpriyatiy $i$ obyedineniy [The Legal Status of
Agricultural Enterprises and Associations]. Chisinau, 1974. $172 \mathrm{p}$.

5. Razuvaev V.N. Soderzhanie i granitsy grazhdanskoy pravosubektnosti [The Content and Boundaries of Civil Legal Personality]. Moscow, 1986. $301 \mathrm{p}$.

6. Rutman T.M. Pravosubektnost gosudarstvennogo promyshlennogo obyedineniya [The Legal Personality of the State Industrial Association]. Izvestiya vuzov. Pravovedenie [News of Universities. Jurisprudence], 1974, no. 6, pp. 38-44.

7. Sobranie postanovleniy Pravitelstva SSSR SP SSSR [A Collection of Decrees of the Government of the USSR - USSR Joint Venture], 1973, no. 7, art. 32; 1974 , no. 8 , art. 38,$39 ; 1975$, no. 21 , art. 45 ; 1976, no. 2 , art. 13; 1979, no. 3 , art. $15 ; 1980$, no. 15 , art. 98 .

8. Palamarchuk M.M., ed. Territorialnaya struktura proizvodstvennykh kompleksov [The Territorial Structure of Production Complexes]. Kiev, $1981.236 \mathrm{p}$.

9. Ukaz Prezidenta RF ot 23 oktyabrya $2000 \mathrm{~g}$. № 1768 «O merakh po obespecheniyu kontsentratsii i ratsionalizatsii oboronnogo proizvodstva $\mathrm{v}$ Rossiyskoy Federatsii» [Decree of the President of the Russian Federation of October 23, 2000 No. 1768 "On Measures to Ensure the Concentration and Rationalization of Defense Production in the Russian Federation"]. Sobranie zakonodatelstva $R F$ [Collection of Legislation of the Russian Federation], 2000, no. 44, art. 4349.

10. Shershenevich G.F. Kurs torgovogo prava. V 4 t. T. 1 [Commercial Law Course. In 4 vols. Vol. 1]. Saint Petersburg, 1908. 491 p.

\section{Information about the Author}

Tatiana K. Krasilnikova, Candidate of Sciences (Jurisprudence), Associate Professor, Head of the Department of Jurisprudence, Volzhsky Branch of Volgograd State University, 40 Let Pobedy St., 11, 404133 Volzhsky, Russian Federation, kun_krasilnikova@mail.ru, https://orcid.org/0000-0002-5869-5859

\section{Информация об авторе}

Татьяна Константиновна Красильникова, кандидат юридических наук, доцент, заведующая кафедрой юриспруденции, Волжский филиал Волгоградского государственного университета, ул. 40 лет Победы, 11, 404133 г. Волжский, Российская Федерация, kun_krasilnikova@mail.ru, https://orcid.org/0000-0002-5869-5859 